\title{
Clostridium difficile infection in an endemic setting in the Netherlands
}

\author{
M. P. M. Hensgens • A. Goorhuis • \\ C. M. J. van Kinschot • M. J. T. Crobach • \\ C. Harmanus • E. J. Kuijper
}

Received: 1 September 2010 /Accepted: 2 December 2010 /Published online: 31 December 2010

(C) The Author(s) 2010. This article is published with open access at Springerlink.com

\begin{abstract}
The purpose of this investigation was to study risk factors for Clostridium difficile infection (CDI) in an endemic setting. In a 34-month prospective case-control study, we compared the risk factors and clinical characteristics of all consecutively diagnosed hospitalised CDI patients $(n=93)$ with those of patients without diarrhoea $(n=76)$ and patients with non-CDI diarrhoea $(n=64)$. The incidence of CDI was 17.5 per 10,000 hospital admissions. C. difficile polymerase chain reaction (PCR) ribotype 014 was the most frequently found type $(15.9 \%)$, followed by types $078(12.7 \%)$ and 015 (7.9\%). Independent risk factors for endemic CDI were the use of second-generation cephalosporins, previous hospital admission and previous stay at the intensive care unit (ICU). The use of third-generation cephalosporins was a risk factor for diarrhoea in general. We found no association of CDI with the use of fluoroquinolones or proton pump inhibitors (PPIs). The overall 30-day mortality among CDI patients, patients without diarrhoea and patients with non-CDI diarrhoea was $7.5 \%, 0 \%$ and $1.6 \%$, respectively. In this endemic setting, risk factors for CDI differed from those in outbreak situations. Some risk factors that have been ascribed to CDI earlier were, in this study, not specific for CDI, but for diarrhoea in general. The 30-day mortality among CDI patients was relatively high.
\end{abstract}

M. P. M. Hensgens and A. Goorhuis contributed equally to this paper.

M. P. M. Hensgens · A. Goorhuis · C. M. J. van Kinschot •

M. J. T. Crobach $\cdot$ C. Harmanus $\cdot$ E. J. Kuijper $(\square)$

Department of Medical Microbiology,

Leiden University Medical Center,

P.O. Box 9600, 2300 RC Leiden, The Netherlands

e-mail: E.J.Kuijper@1umc.nl

\section{Introduction}

Since 2002, outbreaks caused by Clostridium difficile infection (CDI) have been reported in Canada, the USA and Europe, associated with the emergence of a new hypervirulent type. This type has been characterised as North American pulsed-field type 1, restriction endonuclease analysis group type BI, toxinotype III and polymerase chain reaction (PCR) ribotype 027 (type 027) [1-5]. During outbreaks in the USA and Canada, the reported incidences of CDI varied between 155 and 225 per 10,000 hospital admissions [3, 6]. Peak incidences of CDI due to type 027 during outbreaks in the Netherlands were remarkably lower, around 50 per 10,000 hospital admissions [7, 8].

Most recent studies on the risk factors of CDI focussed on outbreaks, whereas less is known about CDI in settings with a low incidence. Well described risk factors for CDI in outbreak situations are prior use of antibiotics, increased disease severity and, in case of outbreaks caused by type 027 , advanced age and prior use of fluoroquinolones [9-11].

The aim of our study was to identify risk factors for CDI in a true endemic setting. A second aim was to establish risk factors specific for CDI, in comparison with factors for diarrhoea in general. To answer these questions, we performed a prospective case-control study at the Leiden University Medical Center, the Netherlands, during a period of 34 months.

\section{Methods}

Patients

From July 2006 through April 2009, all hospitalised patients with CDI were included in the study. Tests for 
CDI were performed daily upon request and on all unformed faecal samples from patients admitted for two days or more, regardless of the physicians' requests. For each hospitalised CDI patient, two controls were included, matched for the ward at which CDI was diagnosed and the time of admission. The controls included one control patient without diarrhoea (control patient) and one control patient with diarrhoea and a negative $C$. difficile toxin test (non-CDI patient). Controls were consecutive patients on the alphabetical ward list.

\section{Definitions}

Definitions as proposed by the European and American Centres of Disease Control were used [2, 12]. Diarrhoea was defined as $\geq 3$ unformed stools per 24 -h period. CDI was defined as the presence of diarrhoea in combination with a positive toxin test for $C$. difficile. A community association was defined as the development of CDI outside the hospital or within $48 \mathrm{~h}$ after admission, without a history of admission in the previous 3 months. We defined diarrhoea as severe when it occurred with one or more of the following: bloody stools, hypovolaemia, fever $\left(\mathrm{T}>38.0^{\circ} \mathrm{C}\right)$ and leukocytosis $\left(>12.0 \times 10^{9} / \mathrm{l}\right)$, hypo-albuminaemia $(<20 \mathrm{~g} / \mathrm{l})$ or pseudomembranous colitis. A complicated course of CDI was defined as: admission to the intensive care unit (ICU), a surgical intervention in association with CDI or death within one month. Mortality was considered to be contributable to CDI when a patient died during admission, partly due to the consequences of CDI.

\section{Isolation and characterisation of Clostridium difficile}

C. difficile toxins in stools were detected by VIDAS $C$. difficile toxin A during the first 12 months of the study and VIDAS toxin $\mathrm{A} / \mathrm{B}$ assay during the ensuing 22 months (bioMérieux, France). Each positive sample was cultured. Available isolates were identified as $C$. difficile using a PCR assay to detect the presence of $g l u \mathrm{D}$ and were PCR ribotyped as previously described $[8,13]$.

\section{Data collection}

Approval was obtained from the Medical Review Ethics Committee to collect demographical and clinical patient data. Information was collected on patients' age, sex, comorbidity, ward of acquisition, disease severity, clinical course and mortality. Furthermore, data were collected on surgery, invasive procedures, admissions, use of antibiotics and other medications in the 3 months prior to CDI. We gathered this information through consultation of the physician in charge, as well as by using patient records and the hospital electronic medical information system. The period of 3 months prior to CDI was determined by calculating backwards from a reference date. For CDI and non-CDI patients, this reference date was defined as the day on which the diarrhoea started. The reference date for control patients was determined by adding the hospitalised period of the matched CDI patient (time between admission and start of diarrhoea) to the admission date of the control patient. Co-morbidity was assessed by both the Charlson co-morbidity index and the ICD-10 classification in ten disease groups, as mentioned in Table 1 [14].

\section{Statistical analysis}

Continuous data were compared between groups using the $t$-test. Pearson's Chi-square test and Fisher's exact test were used for the analysis of proportions. Factors that were associated in the univariate analysis (UVA) with a $p$ value $<0.10$, as well as putative risk factors from earlier studies, were analysed in a multi-variable model. Here, associations were always adjusted for age, sex, ward and Charlson co-morbidity index. To evaluate the effect of medications and interventions on (CDI) diarrhoea, we performed additional adjustments for co-medication and other interventions. When comparing non-CDI patients with control patients, we also corrected for the time between admission and the reference date. Relative risks were estimated as odds ratios (ORs) and presented with a 95\% confidence interval $(95 \% \mathrm{CI})$. Statistical significance was reached with a two-sided $p$-value $<0.05$; trends were defined by a $p$-value $<0.10$. All analyses were performed using the SPSS for Windows software package, version 17.0.

\section{Results}

During the 34-month study period, 93 patients were diagnosed with CDI. The incidence varied from 0 to 43 per 10,000 hospital admissions, with an average of 17.5. During this period, no outbreaks were observed. CDI was community-associated in four patients $(4.3 \%)$. Most patients $(n=30 ; 32.3 \%)$ were hospitalised at the Department of Internal Medicine, followed by the general surgery ward $(n=15 ; 16.1 \%)$. Eighty-nine CDI patients were positive on both toxin testing and culture (95.7\%). Isolates from 63 (67.7\%) patients were available for PCR ribotyping: type 014 was the most frequently found type $(n=10 ; 15.9 \%)$, followed by types $078(n=8 ; 12.7 \%)$ and $015(n=5 ; 7.9 \%)$. Type 027 was not present. Three patients with CDI had a coinfection with an enterovirus, norovirus and Cryptosporidium, respectively.

The 93 CDI patients were compared to 76 control patients and 64 patients with non-CDI diarrhoea. Of all 
Table 1 Baseline characteristics of patients with Clostridium difficile infection (CDI), patients with non-CDI diarrhoea and control patients

\begin{tabular}{|c|c|c|c|c|c|c|}
\hline \multirow[t]{2}{*}{ Risk factors } & \multicolumn{2}{|c|}{ CDI patients $(n=93)^{\mathrm{a}}$} & \multicolumn{2}{|c|}{ Non-CDI patients $(n=64)^{\mathrm{b}}$} & \multicolumn{2}{|c|}{ Control patients $(n=76)^{\mathrm{c}}$} \\
\hline & $n$ & $(\%)$ & $n$ & $(\%)$ & $n$ & $(\%)$ \\
\hline Age $>65$ years & 33 & $(35.5)$ & 18 & $(28.1)$ & 18 & $(23.7)$ \\
\hline Male sex & 56 & $(60.2)$ & 32 & $(50.0)$ & 41 & $(53.9)$ \\
\hline \multicolumn{7}{|l|}{ Charlson co-morbidity index } \\
\hline 0 & 14 & $(15.1)$ & 12 & $(18.8)$ & 19 & $(25.0)$ \\
\hline $1-2$ & 38 & $(40.9)$ & 26 & $(40.6)$ & 32 & $(42.1)$ \\
\hline $3-4$ & 28 & $(30.1)$ & 15 & $(23.4)$ & 18 & $(23.7)$ \\
\hline $5+$ & 13 & $(14.0)$ & 11 & $(17.2)$ & 7 & $(9.2)$ \\
\hline Any underlying disease & 90 & $(96.8)$ & 61 & $(95.3)$ & 70 & $(92.1)$ \\
\hline Malignancy & 24 & $(26.1)$ & 18 & $(28.1)$ & 21 & $(27.6)$ \\
\hline Solid tumour & 10 & $(10.9)$ & 5 & $(7.8)$ & 11 & $(14.5)$ \\
\hline Haematologic malignancy & 15 & $(16.1)$ & 13 & $(20.3)$ & 10 & $(13.2)$ \\
\hline Endocrine diseases & 26 & $(28.0)$ & 16 & $(25.0)$ & 20 & $(26.3)$ \\
\hline Respiratory tract diseases & 14 & $(15.1)$ & 9 & $(14.1)$ & 8 & $(10.5)$ \\
\hline Gastro-intestinal tract diseases & 36 & $(38.7)$ & 16 & $(25.0)$ & 21 & $(27.6)$ \\
\hline Cardiovascular tract diseases & 42 & $(45.2)$ & 27 & $(42.2)$ & 30 & $(39.5)$ \\
\hline Urogenital tract diseases & 42 & $(45.2)$ & 21 & $(32.8)$ & 24 & $(31.6)$ \\
\hline Nervous system diseases & 6 & $(6.5)$ & 4 & $(6.2)$ & 6 & $(7.9)$ \\
\hline Infectious diseases & 13 & $(14.3)$ & 6 & $(9.4)$ & 7 & $(9.2)$ \\
\hline Muscular/connective tissue diseases & 10 & $(10.8)$ & 4 & $(6.2)$ & 7 & $(9.2)$ \\
\hline Other diseases & 36 & $(39.1)$ & 24 & $(37.5)$ & 22 & $(28.9)$ \\
\hline Use of any antibiotics & 87 & $(93.5)$ & 48 & $(75.0)$ & 51 & $(68.0)$ \\
\hline Proton pump inhibitors (PPIs) & 64 & $(68.8)$ & 39 & $(56.2)$ & 38 & $(50.0)$ \\
\hline NSAIDs & 11 & $(11.8)$ & 3 & $(4.7)$ & 7 & $(9.2)$ \\
\hline Immunosuppressive agents & 54 & $(58.8)$ & 38 & $(59.4)$ & 34 & $(44.7)$ \\
\hline Cytostatic agents & 21 & $(22.6)$ & 13 & $(20.3)$ & 11 & $(14.5)$ \\
\hline Nasogastric tube & 39 & $(44.3)$ & 29 & $(45.3)$ & 20 & $(28.2)$ \\
\hline Abdominal surgery & 35 & $(37.6)$ & 24 & $(37.5)$ & 20 & $(28.6)$ \\
\hline Endoscopy & 28 & $(31.5)$ & 16 & $(25.0)$ & 10 & $(13.2)$ \\
\hline Previous admission & 68 & $(74.7)$ & 19 & $(30.2)$ & 30 & $(41.7)$ \\
\hline Previous admission to ICU & 26 & $(28.0)$ & 12 & (18.8) & 5 & $(6.6)$ \\
\hline
\end{tabular}

ICU intensive care unit;NSAIDs non-steroidal anti-inflammatory drugs

${ }^{\mathrm{a}} n$ between 88 and 93

${ }^{\mathrm{b}} n$ between 62 and 64

${ }^{\mathrm{c}} n$ between 71 and 76

patients, physicians responded and records were available; however, in some cases (the exact number is depicted in the footnotes of Table 1), no information about the use of nasogastric intubation, surgery or endoscopy was noted.

In the group of non-CDI patients, two patients were diagnosed with a rotavirus and Giardia lamblia, respectively. Among the other 62 patients, no causal agent was found. CDI patients had a median age of 56 years; non-CDI diarrhoea and control patients had a median age of 50 years. Of the CDI patients, $60 \%$ were male, compared to $50 \%$ and $54 \%$ of the non-CDI and control patients, respectively. The time span between admission and the start of diarrhoea did not significantly differ between CDI and non-CDI patients.

Characteristics and risk factors

We present the baseline characteristics and risk factors for CDI and non-CDI diarrhoea in Tables 1 and 2. The use of antibiotics as a risk factor for CDI and non-CDI is depicted in Table 3. All of the following results reached statistical significance in the multi-variable analysis (MVA), unless otherwise stated. 
Table 2 Crude and adjusted odds ratios (ORs) for the development of CDI and non-CDI diarrhoea

\begin{tabular}{|c|c|c|c|c|}
\hline \multirow[t]{2}{*}{ Risk factors } & \multicolumn{2}{|l|}{ CDI vs. control } & \multicolumn{2}{|l|}{ Non-CDI vs. control } \\
\hline & $\begin{array}{l}\text { Crude odds ratio } \\
(95 \% \text { CI })\end{array}$ & $\begin{array}{l}\text { Adjusted odds ratio } \\
(95 \% \mathrm{CI})\end{array}$ & $\begin{array}{l}\text { Crude odds ratio } \\
(95 \% \text { CI })\end{array}$ & $\begin{array}{l}\text { Adjusted odds ratio } \\
(95 \% \mathrm{CI})\end{array}$ \\
\hline Age $>65$ years & $1.77(0.90-3.49)^{\mathrm{a}}$ & $1.82(0.92-3.62)^{\mathrm{a}}$ & $1.26(0.59-2.69)$ & $1.17(0.54-2.55)$ \\
\hline Male sex & $1.29(0.70-2.39)$ & $1.30(0.70-2.43)$ & $0.85(0.44-1.67)$ & $0.88(0.45-1.72)$ \\
\hline \multicolumn{5}{|l|}{ Charlson co-morbidity index } \\
\hline 0 & Reference & Reference & Reference & Reference \\
\hline $1-2$ & $1.61(0.70-3.72)$ & $1.78(0.73-4.37)$ & $1.29(0.53-3.13)$ & $1.35(0.50-3.66)$ \\
\hline $3-4$ & $2.11(0.85-5.24)$ & $2.42(0.87-6.73)^{\mathrm{a}}$ & $1.32(0.49-3.57)$ & $1.32(0.41-4.30)$ \\
\hline $5+$ & $2.52(0.80-7.95)$ & $2.57(0.76-8.65)$ & $2.49(0.76-8.19)$ & $3.10(0.82-11.7)^{\mathrm{a}}$ \\
\hline Any underlying disease & $2.57(0.62-10.7)$ & $2.45(0.58-10.4)$ & $1.74(0.42-7.27)$ & $2.10(0.46-9.56)$ \\
\hline Haematologic malignancy & $1.27(0.54-3.01)$ & $2.33(0.86-6.23)^{\mathrm{a}}$ & $1.68(0.68-4.15)$ & $2.19(0.70-6.88)$ \\
\hline Urogenital tract diseases & $1.78(0.95-3.36)^{\mathrm{a}}$ & $1.97(0.97-4.02)^{\mathrm{a}}$ & $1.06(0.52-2.16)$ & $0.99(0.42-2.34)$ \\
\hline Other diseases & $1.58(0.83-3.02)$ & $1.47(0.72-3.00)^{\mathrm{a}}$ & $1.47(0.73-2.99)$ & $1.41(0.65-3.07)$ \\
\hline Use of any antibiotics & $6.82(2.62-17.8)^{\mathrm{b}}$ & $5.41(1.79-16.3)^{\mathrm{b}}$ & $1.41(0.67-2.98)$ & $0.99(0.40-2.42)$ \\
\hline Proton pump inhibitors (PPIs) & $2.21(1.18-4.14)^{\mathrm{b}}$ & $1.14(0.51-2.58)$ & $1.29(0.66-2.51)$ & $1.01(0.46-2.22)$ \\
\hline NSAIDs & $1.32(0.49-3.60)$ & $0.86(0.27-2.73)$ & $0.49(0.12-1.96)$ & $0.34(0.07-1.57)$ \\
\hline Immunosuppressive agents & $1.71(0.93-3.15)^{\mathrm{a}}$ & $1.39(0.64-3.06)$ & $1.81(0.92-3.54)^{\mathrm{a}}$ & $1.44(0.64-3.22)$ \\
\hline Cytostatic agents & $1.72(0.77-3.85)$ & $1.61(0.61-4.24)$ & $1.51(0.62-3.64)$ & $1.64(0.58-4.63)$ \\
\hline Nasogastric tube & $2.03(1.04-3.95)^{\mathrm{b}}$ & $1.50(0.66-3.43)$ & $2.11(1.04-4.31)^{\mathrm{b}}$ & $1.77(0.70-4.50)$ \\
\hline Abdominal surgery & $1.51(0.77-2.94)$ & $1.17(0.56-2.45)$ & $1.50(0.73-3.10)$ & $1.28(0.57-2.84)$ \\
\hline Endoscopy & $3.03(1.36-6.75)^{\mathrm{b}}$ & $2.64(1.00-6.96)^{\mathrm{a}}$ & $2.20(0.92-5.27)^{\mathrm{a}}$ & $2.63(0.90-7.64)^{\mathrm{a}}$ \\
\hline Previous admission & $4.14(2.13-8.05)^{\mathrm{b}}$ & $4.49(2.23-9.01)^{\mathrm{b}}$ & $0.61(0.30-1.23)$ & $0.55(0.26-1.17)$ \\
\hline Previous admission to ICU & $5.51(2.00-15.2)^{\mathrm{b}}$ & $5.47(1.95-15.3)^{\mathrm{b}}$ & $3.28(1.09-9.87)^{\mathrm{b}}$ & $2.64(0.83-8.37)^{\mathrm{a}}$ \\
\hline
\end{tabular}

ICU intensive care unit;NSAIDs non-steroidal anti-inflammatory drugs

${ }^{\mathrm{a}}$ Trend detected $(p<0.10)$

${ }^{\mathrm{b}}$ Significant difference $(p<0.05)$

Clinical course

Severe diarrhoea was present among 51 hospitalised patients with CDI (58.6\%) and 25 patients with non-CDI diarrhoea (39.7\%) (OR 2.22; 95\% CI 1.14-4.30). No significant differences between CDI and non-CDI diarrhoeal patients were found regarding the frequency of fever $(55.6 \%$ vs. $43.3 \%)$, bloody stools $(12.2 \%$ vs. $12.9 \%)$ or

Table 3 The use of antibiotics expressed in defined daily doses (DDDs) in patients with CDI and non-CDI diarrhoea and control patients

\begin{tabular}{|c|c|c|c|c|c|c|c|}
\hline \multirow[t]{2}{*}{ Antibiotics } & \multirow{2}{*}{$\begin{array}{l}\text { CDI patients } \\
(n=93)^{\mathrm{a}} \\
n(\%)\end{array}$} & \multirow{2}{*}{$\begin{array}{l}\text { Non-CDI patients } \\
(n=64)^{\mathrm{a}} \\
n(\%)\end{array}$} & \multirow{2}{*}{$\begin{array}{l}\text { Control patients } \\
(n=76)^{\mathrm{a}} \\
n(\%)\end{array}$} & \multicolumn{2}{|l|}{ CDI vs. control } & \multicolumn{2}{|c|}{ Non-CDI vs. control } \\
\hline & & & & $\begin{array}{l}\text { Crude odds ratio } \\
(95 \% \mathrm{CI})\end{array}$ & $\begin{array}{l}\text { Adjusted odds } \\
\text { ratio }(95 \% \mathrm{CI})\end{array}$ & $\begin{array}{l}\text { Crude odds ratio } \\
(95 \% \mathrm{CI})\end{array}$ & $\begin{array}{l}\text { Adjusted odds } \\
\text { ratio }(95 \% \mathrm{CI})\end{array}$ \\
\hline \multicolumn{8}{|l|}{ Cephalosporins } \\
\hline First generation & $13(14.0)$ & $5(7.8)$ & $12(16.0)$ & $0.85(0.36-2.00)$ & $0.79(0.21-3.02)$ & $0.45(0.15-1.34)$ & $0.18(0.04-0.84)^{\mathrm{b}}$ \\
\hline $\begin{array}{l}\text { Second } \\
\text { generation }\end{array}$ & $46(49.5)$ & $20(31.3)$ & $14(21.5)$ & $4.26(2.10-8.67)^{\mathrm{b}}$ & $7.64(2.42-24.2)^{\mathrm{b}}$ & $1.98(0.90-4.34)$ & $0.97(0.31-3.05)$ \\
\hline Third generation & $29(31.2)$ & $12(18.8)$ & $2(3.1)$ & $16.5(3.80-72.1)^{\mathrm{b}}$ & $20.4(3.50-119)^{\mathrm{b}}$ & $8.42(1.81-39.2)^{\mathrm{b}}$ & $9.53(1.66-54.7)^{\mathrm{b}}$ \\
\hline Penicillins & $51(54.8)$ & $22(34.4)$ & $23(30.7)$ & $2.75(1.45-5.20)^{\mathrm{b}}$ & $1.47(0.58-3.72)$ & $1.18(0.58-2.41)$ & $0.69(0.27-1.74)$ \\
\hline Fluoroquinolones & $31(33.3)$ & $21(32.8)$ & $20(26.7)$ & $1.38(0.70-2.69)$ & $0.57(0.20-1.62)$ & $1.34(0.65-2.79)$ & $0.93(0.32-2.70)$ \\
\hline Clindamycin & $5(5.4)$ & $2(3.1)$ & $1(1.3)$ & $4.21(0.48-36.8)$ & $0.75(0.03-17.2)$ & $2.39(0.21-27.0)$ & $2.68(0.14-50.2)$ \\
\hline Vancomycin & $22(23.7)$ & $14(21.9)$ & $7(9.3)$ & $3.01(1.21-7.50)^{\mathrm{b}}$ & $0.51(0.11-2.40)$ & $2.72(1.02-7.23)^{\mathrm{b}}$ & $1.55(0.43-5.62)$ \\
\hline
\end{tabular}

${ }^{\mathrm{a}}$ This information was known for all patients, except one control patient

${ }^{\mathrm{b}}$ Significant difference $(p<0.05)$ detected 
abdominal pain $(54.5 \%$ vs. $48.2 \%)$. CDI patients did, however, have a higher white blood cell count $(\geq 15 \times$ $10^{9} / 1$ : $49.9 \%$ vs. $30.0 \%$, OR $2.28 ; 95 \%$ CI $\left.1.13-4.59\right)$. Most patients with CDI were treated with metronidazole $(n=57$; $63.3 \%)$, two patients $(2.2 \%)$ were treated with vancomycin and in 27 patients $(30.0 \%)$, no specific CDI treatment was initiated. The 30-day and 60-day mortality rates are depicted in Fig. 1. At one month follow-up, a complicated course was observed in nine CDI patients (10.3\%), comprising two colectomies, four ICU admissions due to CDI and seven deaths (7.5\%). CDI contributed directly to three of these deaths, but was not the primary cause. One non-CDI patient $(1.6 \%)$ and none of the control patients died at one month follow-up. No significant associations were detected between the severity of the diarrhoea, treatment or outcome.

\section{Discussion}

In this 34-month prospective case-control study, risk factors for CDI were studied in an endemic setting with a low incidence rate of CDI. The inclusion of a control group of patients with diarrhoea, tested negative for CDI, enabled us to discriminate between risk factors for CDI and for diarrhoea in general.

Common risk factors for CDI outbreaks, such as age above 65 years and a high co-morbidity index, were recognised as trends in our study. This may be due to the fact that these risk factors are of less importance in endemic settings, resulting in a lack of power to discern these risk factors. Other well known risk factors for CDI, such as the

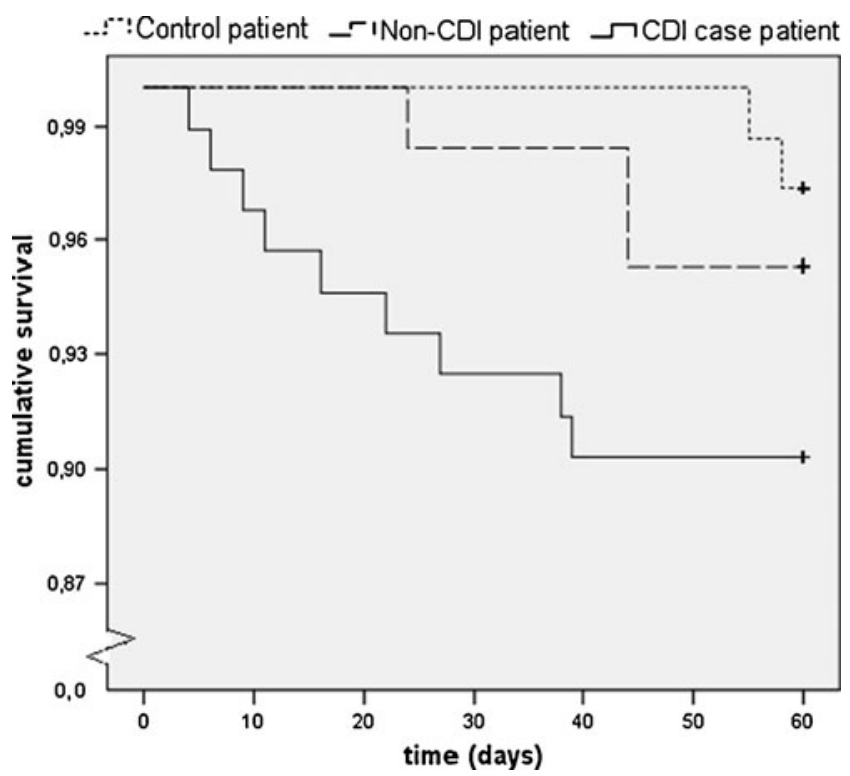

Fig. 1 Survival curve of patients with Clostridium difficile infection (CDI), non-CDI diarrhoea and control patients in a period of 60 days after the reference date use of second-generation cephalosporins and previous (ICU) admission, were also found in this endemic situation [3, 10, 15]. Conversely, the use of fluoroquinolones or proton pump inhibitors (PPIs) was not a risk factor for CDI. Furthermore, the previous use of third-generation cephalosporins was a risk factor for diarrhoea in general.

The CDI incidence in our hospital was lower than that described in other studies in endemic situations, but comparable to the incidence of 18 per 10,000 hospital admissions found in other Dutch hospitals [16]. Recently, a retrospective study analysing risk factors for CDI in an endemic setting in the USA reported an incidence rate of CDI of 106 per 10,000 hospital admissions, which is a factor of 5 higher than what we found in this study [10]. There seems to be a considerable difference, per hospital and per country, in the application of the definition of endemic CDI. Therefore, reported rates of endemic CDI may merely reflect a baseline incidence.

In outbreak situations, the previous use of fluoroquinolones has been recognised as an important risk factor for CDI [9, 11, $17,18]$. This association may be due to disruption of the gut flora by newer fluoroquinolones or the high fluoroquinolone resistance found among hypervirulent type 027 strains [19]. Although fluoroquinolones (mainly ciprofloxacin) were frequently prescribed in this study, we found no association with CDI. An explanation could be that we did not encounter type 027 in our hospital. The most frequently found PCR ribotypes in our study (types 014, 078 and 015) are commonly found in the Netherlands and Europe, and are more susceptible to fluoroquinolones than type 027 [11].

The use of vancomycin was previously recognised as a risk factor for endemic CDI [10]. Instead, in this study, the association between vancomycin and CDI was strongly confounded by the concomitant use of second- and, especially, third-generation cephalosporins (the combination is part of the in-house empirical sepsis therapy) and was not a risk factor for CDI.

PPIs raise the gastric $\mathrm{pH}$, which is associated with enhanced bacterial colonisation of first part of the gastro-intestinal tract. Studies on the use of PPIs in association with CDI revealed conflicting conclusions $[20,21]$. In our study, we found no association of the use of PPIs with CDI. It should be noted that half of the non-CDI and control patients also used PPIs.

Earlier studies have found high contamination and colonisation rates with $C$. difficile spores in the hospital environment, among hospitalised patients and asymptomatic carriers $[22,23]$. A high colonisation pressure on a ward (exposure in time to multiple colonised or infected patients) is associated with an increased risk of CDI [10]. To ensure that CDI and control patients were exposed to a similar colonisation pressure, we selected control patients from the same ward as CDI patients using the same time period between admission and reference date [24]. 
We observed a contributable and overall mortality of $3.2 \%$ and $7.5 \%$ after 30 days follow-up, respectively. These proportions are in between the overall 30-day mortality of $4.7 \%$, found in an endemic setting in Canada, and $20 \%$ mortality after 60 days in a USA study $[25,26]$. These mortality rates are much lower than those reported during outbreaks caused by the type 027 strain $[3,11,26,27]$. In the Netherlands, a complicated course due to type 027 was described in $12.5 \%$, with an attributable mortality rate of $6.3 \%[9]$.

Our study has several limitations. First, we used the presence of toxins in faeces as a screening test for CDI, which is in agreement with the European recommendations [28]. An alternative standard for diagnosing CDI is the detection of $C$. difficile in faeces by toxinogenic culture or PCR. Application of this definition could have resulted in a different case and non-CDI control group. However, none of the patients with non-CDI diarrhoea developed CDI at a later time during admission, which was in accordance with the high negative predictive value of our toxin test. Second, although the endemic incidence found in our study is comparable to that in other Dutch hospitals, it is lower than the incidence rates reported in other studies in endemic situations, which can imply that our findings may not be applicable to endemic situations in other countries $[8,26,29]$.

In conclusion, in this endemic setting, some risk factors for CDI were similar to those found in outbreak situations, but some risk factors that have been ascribed to CDI earlier were, in this study, not specific for CDI, but for diarrhoea in general. The use of fluoroquinolones and PPIs did not influence the risk of endemic CDI. CDI patients were more severely ill than nonCDI diarrhoeal patients, as illustrated by a higher leukocyte count and the relatively high 30- and 60-day mortality. Because CDI is the most important cause of nosocomial diarrhoea, more studies are needed in order to determine the long-term outcome associated with $C$. difficile infections.

Transparency declarations This study was funded by a grant from ZonMw (grant number 4726).

Open Access This article is distributed under the terms of the Creative Commons Attribution Noncommercial License which permits any noncommercial use, distribution, and reproduction in any medium, provided the original author(s) and source are credited.

\section{References}

1. Joseph R, Demeyer D, Vanrenterghem D, van den Berg R, Kuijper E, Delmée M (2005) First isolation of Clostridium difficile PCR ribotype 027, toxinotype III in Belgium. Euro Surveill 10(10): E051020.4
2. Kuijper EJ, Coignard B, Tüll P (2006) Emergence of Clostridium difficile-associated disease in North America and Europe. Clin Microbiol Infect 12(Suppl 6):2-18

3. Loo VG, Poirier L, Miller MA et al (2005) A predominantly clonal multi-institutional outbreak of Clostridium difficile-associated diarrhea with high morbidity and mortality. N Engl J Med 353(23):2442-2449

4. McDonald LC, Killgore GE, Thompson A et al (2005) An epidemic, toxin gene-variant strain of Clostridium difficile. N Engl J Med 353(23):2433-2441

5. Muto CA, Pokrywka M, Shutt K et al (2005) A large outbreak of Clostridium difficile-associated disease with an unexpected proportion of deaths and colectomies at a teaching hospital following increased fluoroquinolone use. Infect Control Hosp Epidemiol 26 (3):273-280

6. Kazakova SV, Ware K, Baughman B et al (2006) A hospital outbreak of diarrhea due to an emerging epidemic strain of Clostridium difficile. Arch Intern Med 166(22):2518-2524

7. Kuijper EJ, van den Berg RJ, Debast S et al (2006) Clostridium difficile ribotype 027, toxinotype III, the Netherlands. Emerg Infect Dis 12(5):827-830

8. Paltansing S, van den Berg RJ, Guseinova RA et al (2007) Characteristics and incidence of Clostridium difficile-associated disease in The Netherlands, 2005. Clin Microbiol Infect 13 (11):1058-1064

9. Goorhuis A, van der Kooi T, Vaessen N et al (2007) Spread and epidemiology of Clostridium difficile polymerase chain reaction ribotype 027 /toxinotype III in The Netherlands. Clin Infect Dis 45 (6):695-703

10. Dubberke ER, Reske KA, Yan Y et al (2007) Clostridium difficileassociated disease in a setting of endemicity: identification of novel risk factors. Clin Infect Dis 45(12):1543-1549

11. Hubert B, Loo VG, Bourgault AM et al (2007) A portrait of the geographic dissemination of the Clostridium difficile North American pulsed-field type 1 strain and the epidemiology of C. difficileassociated disease in Québec. Clin Infect Dis 44(2):238-244

12. McDonald LC, Coignard B, Dubberke E et al (2007) Recommendations for surveillance of Clostridium difficile-associated disease. Infect Control Hosp Epidemiol 28(2):140-145

13. Bidet P, Lalande V, Salauze B et al (2000) Comparison of PCRribotyping, arbitrarily primed PCR, and pulsed-field gel electrophoresis for typing Clostridium difficile. J Clin Microbiol 38 (7):2484-2487

14. Charlson ME, Pompei P, Ales KL et al (1987) A new method of classifying prognostic comorbidity in longitudinal studies: development and validation. J Chronic Dis 40(5):373-383

15. Nelson DE, Auerbach SB, Baltch AL et al (1994) Epidemic Clostridium difficile-associated diarrhea: role of second- and thirdgeneration cephalosporins. Infect Control Hosp Epidemiol 15 (2):88-94

16. Hensgens MP, Goorhuis A, Notermans DW et al (2009) Decrease of hypervirulent Clostridium difficile PCR ribotype 027 in the Netherlands. Euro Surveill 14(45). pii: 19402

17. Bourgault AM, Lamothe F, Loo VG et al (2006) In vitro susceptibility of Clostridium difficile clinical isolates from a multi-institutional outbreak in Southern Québec, Canada. Antimicrob Agents Chemother 50(10):3473-3475

18. Pépin J, Saheb N, Coulombe MA et al (2005) Emergence of fluoroquinolones as the predominant risk factor for Clostridium difficile-associated diarrhea: a cohort study during an epidemic in Quebec. Clin Infect Dis 41(9):1254-1260

19. Weiss K (2009) Clostridium difficile and fluoroquinolones: is there a link? Int J Antimicrob Agents 33(Suppl 1):S29-S32

20. Dial S, Delaney JA, Barkun AN et al (2005) Use of gastric acidsuppressive agents and the risk of community-acquired Clostridium difficile-associated disease. JAMA 294(23):2989-2995 
21. Lowe DO, Mamdani MM, Kopp A et al (2006) Proton pump inhibitors and hospitalization for Clostridium difficile-associated disease: a population-based study. Clin Infect Dis 43(10):1272-1276

22. Dubberke ER, Reske KA, Noble-Wang J et al (2007) Prevalence of Clostridium difficile environmental contamination and strain variability in multiple health care facilities. Am J Infect Control 35(5):315-318

23. McFarland LV, Mulligan ME, Kwok RY et al (1989) Nosocomial acquisition of Clostridium difficile infection. N Engl J Med 320 (4):204-210

24. Goorhuis A, van Dissel JT, Kuijper EJ (2008) Novel risk factors for Clostridium difficile-associated disease in a setting of endemicity? Clin Infect Dis 47(3):429-430

25. Dubberke ER, Butler AM, Reske KA et al (2008) Attributable outcomes of endemic Clostridium difficile-associated disease in nonsurgical patients. Emerg Infect Dis 14(7):1031-1038
26. Pépin J, Valiquette L, Alary ME et al (2004) Clostridium difficile-associated diarrhea in a region of Quebec from 1991 to 2003: a changing pattern of disease severity. CMAJ 171(5):466472

27. Pépin J, Valiquette L, Cossette B (2005) Mortality attributable to nosocomial Clostridium difficile-associated disease during an epidemic caused by a hypervirulent strain in Quebec. CMAJ 173 (9):1037-1042

28. Crobach MJ, Dekkers OM, Wilcox MH et al (2009) European Society of Clinical Microbiology and Infectious Diseases (ESCMID): data review and recommendations for diagnosing Clostridium difficile-infection (CDI). Clin Microbiol Infect 15 (12):1053-1066

29. Alfa MJ, Du T, Beda G (1998) Survey of incidence of Clostridium difficile infection in Canadian hospitals and diagnostic approaches. J Clin Microbiol 36(7):2076-2080 